\title{
Assessment of indoor environment to influence the production of gosling broilers when using sanitary litter
}

\author{
Ramil Fayzrakhmanov, Vladimir Sofronov, Nadezhda Danilova* and Pavel Sofronov \\ Kazan State Academy of Veterinary Medicine named after N.E. Bauman, Kazan 420029, Republic of Tatarstan, Russia
}

\begin{abstract}
The purpose of research and production experiment in the conditions of Akhmetov farm located in the Vysokogorsky district of the Republic of Tatarstan was to study a new sanitary litter material and the effect on the indoor environment, production, viability and feed input required to rear gosling broilers. The experiment found that the new sanitary litter material, made of thermochemically and biotechnologically processed woodworking waste, over the entire period of research was characterized by higher qualities compared to raw sawdust. Accordingly, in the end, the moisture of the said material was lower by $28.5 \%$, the total microbial count and numbers of microscopic fungi were less by $13.3 \%$ and $19.9 \%$, respectively. The said litter material helped to improve the environment in the poultry house, which reduced harmful gases (carbon dioxide $-0.11 \%$ and ammonia $-0.33 \mathrm{mg} / \mathrm{m}^{3}$ ), dust $-0.9 \mathrm{mg} / \mathrm{m}^{3}$ and microorganisms 8.9 thousand $\mathrm{bwt} / \mathrm{m}^{3}$. Ultimately, this contributed to a higher daily live weight gain by $7.51 \%$ and livestock viability by $1.80 \%$, and, sequentially reduced feed input per $1 \mathrm{~kg}$ of live weight gain by $4.98 \%$, as compared with the control.
\end{abstract}

\section{Introduction}

Poultry farming seems to have primary responsibility for providing the population with high-quality meat. It is able to meet this demand in the shortest possible time with minimal cost. Due to its biological characteristics, domestic fowl is well adapted to various husbandry conditions - both favorable and modern intensive technologies. Poultry farming is able to quickly adjust to innovation and adapt to the changing conditions of consumer market. New technologies are beneficial not only from an economic point of view, but also for the ability to ensure the efficient use of various resources, including energy, feed and others [1-3].

Factors such as feeding and housing have a great impact on fowl production. Equipment used in modern poultry farms automatically helps to ensure optimal environment, and, first of all, temperature, humidity, air velocity, gas concentration, etc. [4-5].

Currently, industrial poultry farming greatly relies on the floor brooding of broiler chickens on a deep nonreplaceable litter. Hence, quite high requirements are imposed on the quality of litter material, including moisture absorption, dryness, friability, low thermal conductivity, the ability to absorb toxic from air compounds and inhibit the development of pathogenic microflora, dust conditions, etc. In addition, after removal from the premises it should be used as a fertilizer [6].

Today, various materials are used as litter [7-8], which do not always have good physical and sanitaryhygienic properties and comply with the requirements of modern poultry farming. The litter is not always monitored for infection with pathogenic microflora. Poor litter can lead to various diseases in animals, like pulmonary [9] that can cause various bacterial or fungal diseases [10], and adversely affect the productivity and preservation of fowls [11].

In connection with the above, the study was aimed at the effect of new hygienic bedding material on the productivity of gosling broilers.

\section{Materials and methods}

The study was based on the sanitary-hygienic examination and description of the poultry farm, including technological equipment. The environment was estimated based on the readings of temperature, humidity, gas (carbon dioxide and ammonia) and ambient light sensors installed in the poultry house. The air speed was calculated using a special program installed on a computer, and once a week - with an anemometer. Climate sensors were installed in three places and in the middle of the building, and to prevent damage, they were enclosed with a grid. Output data was automatically transmitted to the computer. If there were any deviations from the optimal parameters, an alarm went off. Dustiness was gravimetrically evaluated. Microbial contamination was assessed through sedimentation methods. The total microbial count and the content of microscopic fungi in the litter were conventionally determined on nutrient media.

The goslings were weighed every 7 days on electronic scales.

Corresponding author: danai58@yandex.ru 
There were 4,500 gosling broilers divided into two groups and selected by exterior and live weight comparison:

- the first group (control) was kept on raw sawdust delivered from the sawmill of the enterprise;

- the second group (experiment) was kept on the trial bedding material developed by OMEGA LLC according to FPS 16.29.14-001-68499146-2018.

The trial bedding material (the second experimental group) was made of planed off wood chips and woodworking waste subjected to thermochemical and biotechnological processing. The material is a dust-free, decontaminated, loose mass from light to dark brown in color with a specific odor, which has a moisture capacity of $280 \%$ and a moisture content of $15 \%$. The dust-free bedding material is resistant to mechanical and biological effects with a pronounced antiseptic and absorption impact. In addition, it is able to absorb harmful gases from the air of livestock premises.

\section{Results}

The effect of target bedding material on gosling broilers was verified through the production experiment in the conditions of Akhmetov farm located in the Vysokogorsky district of the Republic of Tatarstan in July-August 2019. It involved 4,500 geese of Lindov two-way crossing breed.

The goslings were grown in a controlledenvironment environment. Food and water were supplied automatically. The conditions for feeding, keeping and rearing poultry corresponded to the recommendations of All-Russian Research and Technology Institute for Poultry Industry on the Technology for the Production of Gosling Meat [12]. The amount of floor space per one-day goslings was 7.5 fowls per $1 \mathrm{~m}^{2}$, and four-week goslings - 3 fowls per $1 \mathrm{~m}^{2}$. The farm adopted floor poultry brooding on a deep irremovable litter for 30-35 days, followed by transfer to a summer poultry house equipped with lightweight constructions.

The trial fowls from a day to 35 days old were kept in a building $8 \times 60 \mathrm{~m}$ in size, transversely divided by a temporary partition into two halves. Each half was divided into sections designed to reside 100 goslings. Sawdust was used as bedding material for the first control group (first half of the building), and for the second experimental one (second half of the building), the said bedding material was used.

The poultry house had systems for weighing, transporting and storing feed, food and water supply, heating, ventilation, lighting to optimally stimulate food intake and reduce the stress state of fowls, and an automated system for creating the enabling environment. The volume of exhaust and supply air was regulated based on the signals received from the sensors and userspecified information. Fresh air was fed into the premises at the rate of $5 \mathrm{~m}^{3} / \mathrm{h}$ per $1 \mathrm{~kg}$ of live weight.

Climate control and vent adjustment systems maintained optimal indoor environment and took into account:

- age-related needs of the fowls (a young, growing population requires more heat and less fresh air);

- uniform distribution of temperature and humidity in the house;

- outside impacts, including wind, temperature, and humidity.

The inside ventilation system combined natural supply and mechanical exhaust ventilation. The air inflow was due to adjustable transom windows in the longitudinal walls of the house. Indoor air was exhausted through exhaust pipes assembled in the ridge of the roof with fans and temperature sensors.

The premises were heated by a pellet boiler located in the utility room, interlocked with the main building. The pellet boiler, with a capacity of up to $100 \mathrm{~kW}$, was equipped with a water circuit for hot water supply, running at a height of $2.6 \mathrm{~m}$ around the perimeter of all load-bearing walls. To evenly distribute warm air, axial fans with an angle of up to $45^{\circ}$ to the floor were suspended next to the warm water circuit, which ensured a fairly uniform distribution of warm air throughout the house. However, first-day goslings require a higher temperature to be maintained in the poultry house than the above heating can provide. In this regard, electric infrared brooders were suspended at an altitude of 0.9-1.3 m, which provides a local air temperature of $30-32 \mathrm{C}^{\circ}$. The relative indoor humidity was $60-70 \%$.

One of the important factors that greatly influence the body and productivity of fowls is light. The lack of indoor light is compensated by artificial lighting. Lighting sources represented by LED lamps are combined into lighting systems that are controlled centrally. The lighting system in the experiment was adjusted pursuant to feeding and drinking cycles, and primarily depended on the age of the fowls. Illumination at the level of feeders and drinking bowls averaged 40 lux, and the lighting mode was 23 hours of light and 1 hour of darkness. From the fourth to the eighth week, every 2-3 days, the illumination was reduced by 1 lux, and the lighting mode made up a quarter of an hour.

In a water supply system, vacuum drinkers are used up to 10 days. From day 10, goslings are watered from suspended drinking fountains equipped with a valved float chamber to maintain the water level in the fountain. The water in the fountain is running. A watering space is $2 \mathrm{~cm}$ per bird.

The feeding system is composed of round feeders for 16 fowls each with high sides to prevent feed losses by goslings. The feeders are made of high-strength materials that are resistant to various types of cleaning and disinfection deployed in poultry farms. A feeder 
comprises five parts: a plate designed to account for minimal feed losses, a regulator that accurately distributes food, a grill that provides easy access to the feed and a high edge (side) to prevent it from spilling around, a central cone with two openings facilitating dosing adjustment, a latching cap for fixing the cable, stopping the fowls from climbing into the feeder. A feeding space is $3 \mathrm{~cm}$ per bird.

The feeding conditions for all experimental goslings were the same and corresponded to generally accepted diets. The goslings were fed all-in-one feed (AF): AF-31 - for goslings from birth up to 4 weeks and AF-32 - up to 8 weeks, which were delivered from the Glazovsky feed mill. The amount of feed spent to rear goslings was summed in each period based on a daily feed consumption during the entire period of production.

The house was carefully prepared to receive each new batch of goslings. Particular attention was paid to cleaning dust and dirt from air ducts, feed reservoirs, domestic premises, renovations to the premises and equipment maintenance. Houses and droppings were whitened inside and out, disinfected, and sanitized for at least 5 days. Two days before having goslings, the required temperature and humidity conditions were created in the house.

The experiment was aimed at the effect of a new litter material on the indoor environment, viability, production and feed input required to rear goslings of 1 to 35 days old. In addition, moisture and microbial contamination of the litter were determined during the entire period of the experiment.

Sawdust was evenly floored on both halves of the building, based on the $15 \mathrm{~cm}$ thickness of the litter material. Raw sawdust floored in the first half of the building (the first control group), caused high dust content, which led to irritation of the mucous membranes, compared to the second half of the room (second experimental group), where processed sawdust was used. Good quality sawdust was used on both halves of the building. The color indicated sound sawdust that was finely chopped (chip length from 1 to $3 \mathrm{~cm}$ ), without signs of mold and extraneous odors.

Table 1 presents the results including the moisture content in the litter, the total microbial count and the number of microscopic fungi specified during the growing period of gosling broilers.

The data in Table 1 indicate that during the entire research period, the trial litter material ( 2 experimental group) was characterized by higher quality compared to raw sawdust (1 control group). Thus, in the first week of the experiment, the moisture of processed sawdust was $41.4 \%$ lower than that of raw sawdust, in the second $11.1 \%$, the third $-14.7 \%$, the fourth $-16.5 \%$ and the fifth $-28.5 \%$ respectively.

Table 1. Some sanitary and hygienic indicators of bedding material

\begin{tabular}{|c|c|c|c|}
\hline $\begin{array}{c}\text { Age of } \\
\text { fowls, } \\
\text { weeks }\end{array}$ & $\begin{array}{c}\text { Humidity, } \\
\%\end{array}$ & $\begin{array}{c}\text { Total microbial } \\
\text { count, mln. } \\
\text { bwt/m }\end{array}$ & $\begin{array}{c}\text { Number of } \\
\text { microscopic } \\
\text { fungi, mln. } \\
\text { units/l }\end{array}$ \\
\hline & \multicolumn{3}{|c|}{ Raw sawdust $(1$ control group) } \\
\hline $1^{\text {st }}$ day & 11.5 & $5.9 \pm 0.2$ & $0.58 \pm 0.02$ \\
\hline 1 & 17.4 & $13.8 \pm 0.7$ & $2.85 \pm 0.17$ \\
\hline 2 & 19.8 & $103.6 \pm 5.1$ & $26.81 \pm 1.23$ \\
\hline 3 & 22.5 & $487.2 \pm 12.5$ & $41.23 \pm 2.17$ \\
\hline 4 & 23.6 & $924.5 \pm 24.3$ & $54.24 \pm 2.68$ \\
\hline 5 & 29.8 & $4285.3 \pm 195.2$ & $85.31 \pm 4.13$ \\
\hline & Treated sawdust $(2$ experimental group) \\
\hline $1^{\text {st }}$ day & 9.5 & $2.1 \pm 0.1$ & $0.05 \pm 0.01$ \\
\hline 1 & 10.2 & $7.4 \pm 0.4$ & $1.51 \pm 0.09$ \\
\hline 2 & 17.6 & $79.5 \pm 3.8$ & $11.34 \pm 0.94$ \\
\hline 3 & 19.2 & $248.3 \pm 27.9$ & $20.81 \pm 9.85$ \\
\hline 4 & 19.7 & $729.8 \pm 21.8$ & $24.72 \pm 1.23$ \\
\hline 5 & 21.3 & $3715.8 \pm 154.8$ & $68.46 \pm 3.21$ \\
\hline
\end{tabular}

The total microbial count and microscopic fungi increased with the use of bedding material, both in control and in experiment, but in the second case in a smaller amount. Thus, in the first week of the experiment, the total microbial count in the processed sawdust (second experimental group) was lower compared to raw sawdust (1 control group) by $46.4 \%$ and microscopic fungi $64.9 \%$, in the second week -33.3 and $57.7 \%$, the third -49.1 and $49.5 \%$, the fourth 21.1 and $54.4 \%$, the fifth -13.3 and $19.9 \%$, respectively.

Poultry facilities are suited to protect fowls from adverse environmental conditions at any time of the year. For this purpose, it is necessary to create an optimal environment in the house, which is especially important when fowls are kept in closed windowless rooms. When indoor environment is unsatisfactory, fowls are forced to adapt to the environment, which requires higher feed input per unit of live weight gain, and reduces the viability of livestock and poultry production [13]. In this regard, individual indoor parameters were examined in both halves of the house. The findings are presented in Table 2.

Table 2. Basic indoor parameters

\begin{tabular}{|l|c|c|c|c|c|}
\hline \multirow{2}{*}{ Index } & \multicolumn{5}{c|}{ Research schedule, weeks } \\
\cline { 2 - 6 } & $\mathbf{1}$ & $\mathbf{2}$ & $\mathbf{3}$ & $\mathbf{4}$ & $\mathbf{5}$ \\
\hline & \multicolumn{5}{|c|}{1 control group (raw sawdust) } \\
\hline Temperature, $\mathrm{C}^{\mathrm{o}}$ & $31.1 \pm 1.5$ & $29.5 \pm 1.3$ & $28.3 \pm 1.2$ & $27.3 \pm 1.2$ & $26.3 \pm 1.1$ \\
\hline Relative moisture, $\mathrm{R} \%$ & $58.7 \pm 2.9$ & $64.8 \pm 2.8$ & $69.8 \pm 2.7$ & $71.6 \pm 3.4$ & $75.8 \pm 4.7$ \\
\hline Air velocity, $\mathrm{m} / \mathrm{s}$ & $0.01 \pm 0.01$ & $0.16 \pm 0.01$ & $0.17 \pm 0.02$ & $0.25 \pm 0.02$ & $0.34 \pm 0.02$ \\
\hline Ammonia content, $\mathrm{mg} / \mathrm{m}^{3}$ & $0.9 \pm 0.1$ & $5.9 \pm 0.2$ & $10.5 \pm 0.4$ & $12.1 \pm 0.5$ & $14.8 \pm 0.7$ \\
\hline Carbon dioxide content, \% & $0.1 \pm 0.01$ & $0.12 \pm 0.01$ & $0.19 \pm 0.02$ & $0.23 \pm 0.02$ & $0.29 \pm 0.03$ \\
\hline Dust content, $\mathrm{mg} / \mathrm{m}^{3}$ & $0.5 \pm 0.02$ & $0.9 \pm 0.03$ & $1.2 \pm 0.06$ & $1.8 \pm 0.09$ & $2.1 \pm 0.11$ \\
\hline Microbial count, thousand bwt/m ${ }^{3}$ & $14.2 \pm 0.7$ & $19.7 \pm 0.9$ & $23.1 \pm 1.2$ & $27.2 \pm 1.4$ & $31.2 \pm 1.6$ \\
\hline & \multicolumn{5}{|c|}{2 experimental group (treated sawdust) } \\
\hline
\end{tabular}




\begin{tabular}{|l|c|c|c|c|c|}
\hline Temperature, $\mathrm{C}^{\mathrm{o}}$ & $31.2 \pm 1.4$ & $29.8 \pm 1.4$ & $28.5 \pm 1.3$ & $27.1 \pm 1.3$ & $25.9 \pm 1.1$ \\
\hline Relative moisture, $\mathrm{R} \%$ & $57.2 \pm 2.5$ & $59.3 \pm 2.3$ & $62.6 \pm 2.7$ & $65.4 \pm 2.9$ & $67.2 \pm 3.4$ \\
\hline Air velocity, $\mathrm{m} / \mathrm{s}$ & $0.01 \pm 0.01$ & $0.16 \pm 0.01$ & $0.17 \pm 0.02$ & $0.25 \pm 0.02$ & $0.32 \pm 0.02$ \\
\hline Ammonia content, $\mathrm{mg} / \mathrm{m}^{3}$ & $0.5 \pm 0.01$ & $2.8 \pm 0.09$ & $4.2 \pm 0.19$ & $5.3 \pm 0.21$ & $8.7 \pm 0.23$ \\
\hline Carbon dioxide content, \% & $0.05 \pm 0.01$ & $0.09 \pm 0.01$ & $0.12 \pm 0.02$ & $0.15 \pm 0.02$ & $0.18 \pm 0.03$ \\
\hline Dust content, $\mathrm{mg} / \mathrm{m}^{3}$ & $0.3 \pm 0.01$ & $0.5 \pm 0.02$ & $0.7 \pm 0.03$ & $1.0 \pm 0.04$ & $1.2 \pm 0.06$ \\
\hline Microbial count, thousand bwt $/ \mathrm{m}^{3}$ & $9.8 \pm 0.5$ & $13.5 \pm 0.6$ & $17.2 \pm 0.8$ & $19.5 \pm 0.9$ & $22.3 \pm 1.1$ \\
\hline
\end{tabular}

The data in Table 2 indicate that raw sawdust in the first control group contributed to the deterioration of the indoor parameters. Thus, the humidity rose by $1.5-8.6 \%$, carbon dioxide content - by $0.03-0.11 \%$, ammonia by $0.07-0.33 \mathrm{mg} / \mathrm{m}^{3}$, dust - by $0.9 \mathrm{mg} / \mathrm{m}^{3}$ and microorganisms - by 8.9 thousand $\mathrm{bwt} / \mathrm{m}^{3}$, compared with the second experimental group, respectively.

Thus, the indoor parameters in two halves of the livestock building indicate that raw sawdust used as bedding material (the first control group) contributed to higher humidity, harmful gases, dust pollution and microbial contamination, compared with the use of treated sawdust ( second experimental group).

The main goal of industrial poultry farming is to produce meat. Therefore, there was a need to compare the meat productivity of gosling broilers depending on the type of sawdust used as bedding material. The experimental goslings were weekly weighed on electronic scales to monitor the poultry production. The results are presented in Table 3.

Table 3. Meat production from gosling broilers when grown on different types of sawdust used as bedding material

\begin{tabular}{|c|c|c|}
\hline \multirow{2}{*}{ Index } & \multicolumn{2}{|c|}{ Group } \\
\cline { 2 - 3 } & $\begin{array}{c}\text { 1 - control } \\
\text { (raw } \\
\text { sawdust) }\end{array}$ & $\begin{array}{c}\text { 2- experiment } \\
\text { (treated } \\
\text { sawdust) }\end{array}$ \\
\hline Live weight, days: & & \\
\hline 1 & $105 \pm 6$ & $105 \pm 7$ \\
\hline 7 & $315 \pm 21$ & $342 \pm 19$ \\
\hline 14 & $750 \pm 37$ & $794 \pm 41$ \\
\hline 21 & $1310 \pm 59$ & $1396 \pm 62$ \\
\hline 28 & $1920 \pm 91$ & $2054 \pm 94$ \\
\hline 35 & $2550 \pm 145$ & $2734 \pm 148$ \\
\hline Daily live weight gain, g & $69.86 \pm 2,9$ & $75.11 \pm 2.7$ \\
\hline Viability, \% & 94.5 & 96.3 \\
\hline $\begin{array}{c}\text { Feed input per 1 kg of live } \\
\text { weight gain, kg }\end{array}$ & 2.61 & 2.48 \\
\hline
\end{tabular}

The studies show that the use of treated sawdust as bedding material in the second half of the building (the second experimental group) contributed to greater average daily gain in gosling broilers by $7.51 \%$ and the viability of the livestock - by $1.8 \%$. This also reduced feed input per $1 \mathrm{~kg}$ of live weight gain by $4.98 \%$ compared with the first control group kept on the raw sawdust.

\section{Discussion}

In summary, the use of the said litter material (the second experimental group), made of planed off wood chips and woodworking waste subjected to thermochemical and biotechnological processing, improved individual sanitary and hygienic indicators of litter material throughout the entire experiment. This contributed to the improvement of individual microclimate parameters and, ultimately, resulted in the advanced meat production, viable livestock, and reduced feed input per unit of live weight gain.

Thus, the moisture content of the said bedding material from the treated sawdust finally was lower by $28.5 \%$, the total microbial count - by $13.3 \%$ and the microscopic fungi - by $19.9 \%$, respectively, as compared to raw sawdust. A possible reason for the greater microbial count and microscopic fungi in the raw litter (1 control group), was its higher moisture and low moisture capacity, which is consistent with the literature [14]. Most likely, this is due to more pronounced decomposition behavior of raw sawdust (first control group) compared to processed sawdust (second experimental group), which inevitably entails a greater release of harmful gases, dust and microorganisms.

The resulting higher quality of trial bedding material contributed to the improvement of individual indoor parameters. In the end, the relative humidity in the second experimental group was $8.6 \%$ lower than the control, the carbon dioxide content - by $0.11 \%$, ammonia - by $0.33 \mathrm{mg} / \mathrm{m}^{3}$, dust - by $0.9 \mathrm{mg} / \mathrm{m}^{3}$ and microorganisms - by 8.9 thousand bwt $/ \mathrm{m}^{3}$, respectively. Improving the environment in the second experimental group contributed to a higher daily live weight gain of gosling broilers by $7.51 \%$ and livestock viability by $1.8 \%$, as well as reduced feed intake by $1 \mathrm{~kg}$ of weight gain - by $4.98 \%$, as compared to the goslings of the first control group managed on raw sawdust, which is consistent with the literature [15].

\section{Conclusion}

Thus, throughout the study period, the said litter material thermochemically and biotechnologically treated was characterized by higher qualities compared to raw sawdust. Eventually, the moisture content was lower by $28.5 \%$, the total microbial count - by $13.3 \%$ and microscopic fungi - by $19.9 \%$, respectively. The use of a new sanitary litter contributed to the improvement of certain indoor parameters in the poultry house, which resulted in a reduction of harmful gases (carbon dioxide $-0.11 \%$ and ammonia $-0.33 \mathrm{mg} / \mathrm{m}^{3}$ ), dust $0.9 \mathrm{mg} / \mathrm{m}^{3}$ and microorganisms -8.9 thousand $\mathrm{bwt} / \mathrm{m}^{3}$, which ultimately increased daily live weight gain of gosling broilers by $7.51 \%$, livestock viability - by $1.8 \%$, and, accordingly, decreased feed input per $1 \mathrm{~kg}$ of live weight gain by $4.98 \%$, compared to the control.

\section{References}

1. D. Farrell, ISBN 978-92-5-108067-2 (PDF) @ C FAO (2013). Retrieved from: www.fao.org/contact-us/ 
2. C.G. Scanes (2007). Retrieved from: https://www.researchgate.net/publication/5890368

3. M.-L. Augère-Granier, Research Service PE 644.195, 23 p. (2019)

4. E.L. Kuznetsova, P.V. Sofronov, N.I. Danilova, Trends and Prospects for the Development of 21st Century Science, in: Proc. of the Int. Sci.-pract. Conf., in 2 volumes, vol. 2, pp. 84-87 (Syzran, 28 January 2016) (ICIR Omega Science, Ufa, 2016),

5. V.G. Sofronov, E.L. Kuznetsova, N.M. Shamilov, N.I. Danilova, Sci. Notes of Kazan State Acad. of Veter. Med. named after N.E. Bauman 225, 144-148 (2016)

6. R.G. Garcia, Paz I.C.L Almeida, F.R. Caldara, I.A. Nääs, D.F. Pereira, V.M.O.S. Ferreira, Brazilian J. of Poultry Sci. 14(2), 71-158 (Apr - Jun 2012)

7. J.L. Atencio, J.A. Fernández, A.G. Gernat, J.G. Murillo, Int. J. of Poultry Sci. 9(3), 240-243 (2010)
8. G. Sharma, A. Khan, S. Singh, A.K. Anand, Veter. World 8(10), 1219-1224 (2015)

9. G. Ayars, L. Altman, C. Frazier, E. Chi, J. of Allergy and Clinical Immunol. 83(3), 610-618 (1989)

10. K. Macklin, J. Hess, S. Bilgili, R. Norton, The J. of Appl. Poultry Res. 14(2), 238-245 (2005)

11. A. Hafeez, S.M. Suhail, F.R. Durrani, D. and J. Sarhad, J Agricult. 25(4), 581-586 (2009)

12. Sh.A. Imangulov, I.A. Egorov, T.M. Okolelova, Guidelines (Sergiev Posad, 2009), 144 p.

13. M. Toghyani, A. Gheisari, M. Modaresi, S. Tabeidian, M. Toghyani, Appl. Animal Behaviour Sci. 122(1), 48-52 (2010)

14. T. Whiteside, J. Thigpen, G. Kissling, M. Grant, D. Forsythe, J. of the Amer. Associat. for Lab. Animal Sci. 49(2), 184-189 (2010)

15. A.P.S. Dhaliwal, B.S. Dhillon, J.S. Brar, Int. J. Curr. Microbiol. App. Sci. 7(12), 1041-1045 (2018) 